\title{
Evaluation of the Psychometric Properties of the Scale A-ONE: An Italian Cross-Sectional Study
}

\author{
Margherita Cerone, ${ }^{1}$ Marco Tofani $\left(\mathbb{D},{ }^{2}\right.$ Giovanni Fabbrini $\left(\mathbb{D},{ }^{3,4}\right.$ Giulia Marcellini, ${ }^{5}$ \\ Anna Berardi $\left(\mathbb{D},{ }^{3}\right.$ Claudia Conti, ${ }^{5}$ Rita De Santis, ${ }^{6}$ Donatella Valente, ${ }^{3,4}$ \\ and Giovanni Galeoto ${ }^{3,4}$ \\ ${ }^{1}$ San Giovanni Battista-Cavalieri di Malta, Rome, Italy \\ ${ }^{2}$ Neurorehabilitation Unit, Department of Intensive Neurorehabilitation and Robotics, Bambino Gesù Children's Hospital, Italy \\ ${ }^{3}$ Department of Human Neurosciences, Sapienza University of Rome, Italy \\ ${ }^{4}$ IRCCS Neuromed Pozzilli, Italy \\ ${ }^{5}$ Sapienza University of Rome, Rome, Italy \\ ${ }^{6}$ Department of Anatomical, Histological, Forensic and Orthopedic Sciences, "Sapienza” University of Rome, Italy
}

Correspondence should be addressed to Marco Tofani; marco.tofani@uniroma1.it

Received 17 September 2020; Revised 8 February 2021; Accepted 8 March 2021; Published 18 March 2021

Academic Editor: Stefania Costi

Copyright (c) 2021 Margherita Cerone et al. This is an open access article distributed under the Creative Commons Attribution License, which permits unrestricted use, distribution, and reproduction in any medium, provided the original work is properly cited.

\begin{abstract}
Purpose. This study is aimed at validating the A-ONE scale in an Italian population with Central Nervous System (CNS) dysfunction. Material and Methods. Between May and November 2018, people aged between 60 and 90 with CNS dysfunction were recruited in a hospital in Rome, Italy. Patients were observed and evaluated during the activities of daily living. Internal consistency and reliability were evaluated with Cronbach's coefficient alpha and intraclass correlation coefficient, respectively. As measured with Pearson's correlation coefficient, the validity was examined comparing results of the A-ONE with the Barthel index. Responsiveness was evaluated 30 days after the first administration. Results. A total of 70 people having a diagnosis of neurological disorders were evaluated. The internal consistency showed Cronbach's coefficient alpha ranging from 0.634 to 0.959. The measurement of reliability varied from 0.984 to 0.997 for intrarater and from 0.979 to 0.998 for interrater. Pearson's correlation coefficient between the A-ONE and the Barthel index and the responsiveness showed statistically significant values $(p<0.01)$. Conclusions. The present study provides preliminary evidence of reliability, validity, and responsiveness of the A-ONE when using elderly people with CNS dysfunction.
\end{abstract}

\section{Introduction}

Occupational therapy is an integral part of the rehabilitation process of people with brain injuries. Central Nervous System (CNS) diseases are the dysfunction of any brain component (including the cerebral hemispheres, the diencephalon, the brain stem, and the cerebellum) or the spinal cord. Several causes of these dysfunctions result in neurobehavioral deficits, including vascular disorders, metabolic disorders, head trauma, infections, toxins, brain tumors, and degeneration of the nervous system [1]. The dysfunction of the CNS is evident in patients with various diagnoses. In Italy, diseases of the nervous system that require a specialist neurologist intervention show an incidence of $7.5 \%$ per year and a prevalence of $30 \%$ [2].

Regarding patient evaluation, in rehabilitation, there are several rating scales. To test which skills and abilities the individual has lost or maintained, the occupational therapist takes its point of reference, the activities of daily living (ADL) [3-5]. Traditionally, this type of evaluation is 
used exclusively to indicate the level of independence and need for assistance. Rather, it is possible using the ADLfocused Occupation-based Neurobehavioral Evaluation (A-ONE) [6] to grasp the reasons for lack of independence or understand how or why this dysfunction interferes with daily performance.

The A-ONE was published for the first time in 1990 by occupational therapist Guðrún Árnadóttir. She aimed to create a tool based on an occupation to simultaneously evaluate the performance in ADL and the impact of the neurobehavioral impairment, which limits the performance in the natural environment [7-9].

This tool is designed to be used with people aged above 16 , with neurological and neurocognitive disorders due to a CNS dysfunction (e.g., stroke, head trauma, Alzheimer's disease, and Parkinson's disease), and is specific to occupational therapists.

The usage of the A-ONE requires the observation of the performance during ADL. The A-ONE is composed of an ADL scale, termed the Functional Independence scale, and a Neurobehavioral Impairment scale, composed of two subscales, the Neurobehavioral Specific Impairment subscale and the Neurobehavioral Pervasive Impairment subscale [10]. A certification course lasting five days is required for using the tool effectively. Training courses have been organized all over the world since 2013, including in Japan, Iceland, Holland, the USA, Denmark, Canada, Italy, Korea, and Norway (http://www.a-one.is). Other than the original version, the A-ONE was translated and validated for Japanese [11] and Korean [12] population. Psychometric property studies reveal good validity and reliability [10-12].

The study is aimed at testing the scale's psychometric properties for the Italian context, namely, the internal consistency, reliability, validity, and responsiveness. Therefore, this study's expected outcome is to provide a useful tool to most occupational therapists who will evaluate patients with brain dysfunction to verify functional independence concerning neurobehavioral impairments.

\section{Material and Methods}

The study was conducted by a research group composed of medical doctors and rehabilitation professionals of the Sapienza University of Rome, Tor Vergata University of Rome, and from the Rehabilitation and Outcome Measure Assessment (ROMA) Association. In the last few years, ROMA has dealt with the validation of many outcome measures in Italy $[4,5,13-24]$.

2.1. Description of the Sample. The people were recruited from May to November 2018 at the rehabilitation center at the San Giovanni Battista-Cavalieri di Malta, Rome. Sample size dimension was defined confronting other validity studies: the validation study of the Japanese version of the A-ONE (sample 65) [11] and the validity study for cerebrovascular accident (sample 45) [25]. Therefore, the research group was defined as a minimum sample size of 65 people. The A-ONE was created to guide the occupational therapist in the intervention planning. However,
Arnadottir and Fisher (2008) verify that one of the AONE subscales (ADL scales) could also be an outcome measure in terms of the occupational therapist intervention's efficacy. In our clinical practice, the A-ONE was used as a guiding tool for OT practice, and an outcome measure. To be admitted to the study, patients had to meet the following inclusion criteria: diagnosis of a neurological disorder of the CNS, being 60 to 90 years old, and a signature for the informed consent. All people who had other medical conditions or comorbidities (e.g., hip prosthetics) were excluded. Before the evaluation, the patient was provided information regarding the study. Once the patient clarified any doubts about objectives and procedures, they were asked to sign an informed consent $[22,26]$.

2.2. Measurements. A-ONE: the A-ONE is commonly used for adults that have acquired CNS dysfunction. A-ONE is composed of two scales: the Functional Independence scale and the Neurobehavioral Impairment scale.

The Functional Independence scale consists of $20 \mathrm{ADL}$ items and two communication items. It is a 5-category ordinal rating scale ranging from 0 to 4 used to score the observed level of assistance needed to overcome the impact of impairment on ADL performance $(0=$ full assistance needed, $1=$ minimum to considerable physical assistance needed, $2=$ verbal assistance needed, $3=$ supervision needed, and $4=$ independent) [8].

The Neurobehavioral Impairment scale is used to assess the extent to which the consequences of neurobehavioral alterations affect performance in daily living activities. The Neurobehavioral Impairment scale contains two subscales, the Neurobehavioral Specific Impairment subscale comprised of 46 rating scale items and the Neurobehavioral Pervasive Impairment subscale comprised of 31 dichotomous items [6]. Most of the specific impairment items are independently rated more than once in connection with the performance of different ADL tasks (e.g., motor apraxia-dressing, motor apraxia-grooming and hygiene, motor apraxia-transfers, and mobility, and motor apraxia-feeding). The Neurobehavioral Pervasive Impairment subscale items are rated only once based on an observed error in at least one ADL task. The 5 ADL tasks observed (dressing, grooming and hygiene, transfers and mobility, feeding, and communication) are referred to as ADL domains. Persons are scored based on assistance to overcome the occupational errors during ADL task performance [7].

The Barthel's index [26] provides a score which is indicative of the capacity of the patient for autonomy: feeding, bathing, care of appearance, dressing, using the toilet, moving from wheelchair to bed and vice versa, walk on surfaces such as the floor, climb up and down the stairs, and control the bowel and bladder. The scores assigned to each function can be 15,10 , and 5 . The maximum score is assigned only if the patient performs the task completely independently, without the presence of personal assistance. Otherwise, a value down to zero is assigned. The maximum score for each function is assigned to have a total score of 100; such a score would indicate complete independence in daily living activities (Castiglia et al., 2017). 
TABle 1: Demographic characteristics of the 70 patients enrolled in the study.

\begin{tabular}{|c|c|}
\hline Variable & Population $=70$ \\
\hline Gender female $\mathrm{n}^{\circ}(\%)$ & $46(66)$ \\
\hline Age mean \pm SD (range) & $74.66 \pm 7.88(60-89)$ \\
\hline \multicolumn{2}{|l|}{ Diagnosis $n^{\circ}(\%)$} \\
\hline Stroke & $51(73)$ \\
\hline Head trauma & $6(9)$ \\
\hline Parkinson's disease & $13(19)$ \\
\hline \multicolumn{2}{|l|}{ Marital status $\mathrm{n}^{\circ}(\%)$} \\
\hline Married & $37(53)$ \\
\hline Divorced & $4(6)$ \\
\hline Unmarried & $5(7)$ \\
\hline Separate & $5(7)$ \\
\hline Widower & $19(27)$ \\
\hline \multicolumn{2}{|l|}{ Employment status $\mathrm{n}^{\circ}(\%)$} \\
\hline Employed & $12(17)$ \\
\hline Unemployed & $19(27)$ \\
\hline Retired & $39(56)$ \\
\hline \multicolumn{2}{|c|}{ Neurobehavioral pervasive impairment ${ }^{*} \mathrm{n}^{\circ}(\%)$} \\
\hline Lability & $2(2.9)$ \\
\hline Euphoria & $1(1.4)$ \\
\hline Apathy & $12(17.1)$ \\
\hline Depression & $14(20)$ \\
\hline Frustration & $8(11.4)$ \\
\hline Restlessness & $2(2.9)$ \\
\hline Concrete thinking & $5(7.1)$ \\
\hline Decreased insight & $7(10)$ \\
\hline Impaired judgment & $9(12.9)$ \\
\hline Confusion & $10(14.3)$ \\
\hline Impaired alertness & $2(2.9)$ \\
\hline Impaired attention & $3(4.3)$ \\
\hline Distractibility & $1(1.4)$ \\
\hline Impaired initiative & $17(24.3)$ \\
\hline Impaired motivation & $20(28.6)$ \\
\hline Performance latency & $20(28.6)$ \\
\hline Absent mindedness & $2(2.9)$ \\
\hline Short-term memory & $6(8.6)$ \\
\hline Long-term memory & $5(7.1)$ \\
\hline Disorientation & $9(12.9)$ \\
\hline
\end{tabular}

2.3. Reliability and Validity. The patients were observed and evaluated during the ADL in the morning by two certified occupational therapists who have completed the A-ONE course.

For the intrarater reliability, the patient was evaluated twice by the same rater, one day after the first evaluation. A short evaluation time ( 1 day) was chosen because the study setting included acute and postacute units. For interrater reliability, the two OT evaluated the same patient at the same time. Raters were blinded to each other's results. To analyze reliability, the intraclass correlation coefficient (ICC) was
TABLE 2: Internal consistency reliability for the different domains.

\begin{tabular}{lccc}
\hline & $\begin{array}{c}\mathrm{N}^{\circ} \text { of } \\
\text { items }\end{array}$ & $\begin{array}{c}\text { Cronbach's } \\
\text { alpha }\end{array}$ & $\begin{array}{c}\text { Cronbach's alpha based on } \\
\text { standardized elements }\end{array}$ \\
\hline $\begin{array}{l}\text { Dressing } \\
\begin{array}{l}\text { Grooming and } \\
\text { hygiene }\end{array}\end{array}$ & 5 & 0.926 & 0.927 \\
$\begin{array}{l}\text { Transfers and } \\
\text { mobility }\end{array}$ & 5 & 0.881 & 0.884 \\
$\begin{array}{l}\text { Feeding } \\
\text { Communication }\end{array}$ & 2 & 0.930 & 0.930 \\
Total & 22 & 0.959 & 0.851 \\
\hline
\end{tabular}

TABle 3: Cronbach's alpha of the scale A-ONE (items 1-22) eliminating individual items.

\begin{tabular}{|c|c|c|c|c|}
\hline & $\begin{array}{l}\text { Medium } \\
\text { scale if it } \\
\text { deleted the } \\
\text { item }\end{array}$ & $\begin{array}{c}\text { Variance } \\
\text { scale if it } \\
\text { deleted the } \\
\text { item }\end{array}$ & $\begin{array}{c}\text { Correlation } \\
\text { item-total } \\
\text { correct }\end{array}$ & $\begin{array}{c}\text { Cronbach's } \\
\text { alpha if it } \\
\text { deleted the } \\
\text { item }\end{array}$ \\
\hline Item1-D & 47.04 & 430.389 & 0.773 & 0.956 \\
\hline Item2-D & 47.70 & 426.851 & 0.826 & 0.956 \\
\hline Item3-D & 47.86 & 428.936 & 0.785 & 0.956 \\
\hline Item4-D & 47.76 & 424.592 & 0.848 & 0.955 \\
\hline Item5-D & 47.21 & 429.852 & 0.738 & 0.957 \\
\hline Item6-G/H & 46.54 & 435.962 & 0.739 & 0.957 \\
\hline Item7-G/H & 46.44 & 439.497 & 0.658 & 0.958 \\
\hline Item8-G/H & 46.84 & 427.149 & 0.776 & 0.956 \\
\hline Item9-G/H & 48.69 & 441.755 & 0.564 & 0.959 \\
\hline Item $10-\mathrm{G} / \mathrm{H}$ & 48.00 & 413.681 & 0.886 & 0.955 \\
\hline Item $11-\mathrm{G} / \mathrm{H}$ & 48.81 & 441.603 & 0.701 & 0.957 \\
\hline Item12-T/M & 47.11 & 427.668 & 0.784 & 0.956 \\
\hline Item13-T/M & 47.40 & 421.142 & 0.895 & 0.955 \\
\hline Item14-T/M & 46.71 & 429.135 & 0.749 & 0.956 \\
\hline Item15-T/M & 47.90 & 410.932 & 0.885 & 0.955 \\
\hline Item16-T/M & 48.63 & 435.280 & 0.712 & 0.957 \\
\hline Item17-F & 45.83 & 455.883 & 0.536 & 0.959 \\
\hline Item $18-\mathrm{F}$ & 45.83 & 456.724 & 0.514 & 0.959 \\
\hline Item $19-\mathrm{F}$ & 46.06 & 448.750 & 0.620 & 0.958 \\
\hline Item $20-\mathrm{F}$ & 47.83 & 430.173 & 0.634 & 0.958 \\
\hline Item 21-C & 45.64 & 469.131 & 0.314 & 0.960 \\
\hline Item22-C & 46.16 & 464.656 & 0.330 & 0.960 \\
\hline
\end{tabular}

$\mathrm{D}=$ dressing; $\mathrm{G} / \mathrm{H}=$ grooming and hygiene; $\mathrm{T} / \mathrm{M}=$ transfers and mobility; $\mathrm{F}=$ feeding; $\mathrm{C}=$ communication.

used. The scale is considered to be reliable if the ICC is higher than 0.70. The A-ONE scale's internal consistency was assessed through Cronbach's coefficient alpha, whose value can vary from 0 to 1 ; it is considered significant when greater than $0.70[27,28]$.

To compare the A-ONE scores, Barthel's index was used as a gold standard for construct validity. Pearson's correlation coefficient was calculated to analyze validity, which measures the degree of association between two variables, resulting in values between -1 and 1 [29]. 
TABLE 4: Test-retest reliability intraoperator (after 24 hours) for different domains.

\begin{tabular}{lcccrrr}
\hline & Test $($ mean \pm SD $)$ & Retest $($ mean \pm SD) & ICC & \multicolumn{2}{c}{ IC 95\% } \\
\hline Dressing & $9.6 \pm 6.3$ & $9.71 \pm 6.2$ & $0.994^{\mathrm{c}}$ & 0.990 & 0.996 & $<0.001$ \\
Grooming and hygiene & $11.24 \pm 6.7$ & $11.46 \pm 6.6$ & $0.997^{\mathrm{c}}$ & 0.995 & 0.998 & $<0.001$ \\
Transfers and mobility & $9.39 \pm 6.7$ & $9.51 \pm 6.5$ & $0.996^{\mathrm{c}}$ & 0.994 & 0.998 & $<0.001$ \\
Feeding & $12.17 \pm 3.6$ & $12.36 \pm 3.6$ & $0.992^{\mathrm{c}}$ & 0.987 & 0.995 & $<0.001$ \\
Communication & $7.06 \pm 1.2$ & $7.13 \pm 1.2$ & $0.984^{\mathrm{c}}$ & 0.975 & 0.990 & $<0.001$ \\
\hline
\end{tabular}

TABLE 5: Test-retest reliability interoperator (two operators at the same time) for different domains.

\begin{tabular}{lcccrrr}
\hline & Test $($ mean \pm SD $)$ & Retest $($ mean \pm SD $)$ & ICC & \multicolumn{2}{c}{ IC 95\% } \\
\hline Dressing & $9.57 \pm 6.3$ & $9.44 \pm 6.2$ & $0.996^{\mathrm{c}}$ & 0.994 & 0.998 & 0.001 \\
Grooming and hygiene & $11.24 \pm 6.7$ & $11.14 \pm 6.7$ & $0.998^{\mathrm{c}}$ & 0.996 & 0.998 & 0.001 \\
Transfers and mobility & $9.39 \pm 6.7$ & $9.39 \pm 6.7$ & $0.996^{\mathrm{c}}$ & 0.994 & 0.998 & 0.001 \\
Feeding & $12.17 \pm 3.6$ & $12.17 \pm 3.7$ & $0.989^{\mathrm{c}}$ & 0.982 & 0.993 & 0.001 \\
Communication & $7.06 \pm 1.2$ & $7.10 \pm 1.3$ & $0.979^{\mathrm{c}}$ & 0.967 & 0.987 & 0.001 \\
\hline
\end{tabular}

TABle 6: Pearson's correlation coefficient for the totals of each A-ONE domain with respect to the total of Barthel's index.

\begin{tabular}{lcccccc}
\hline & & Dressing & Grooming and hygiene & Transfers and mobility & Feeding & Communication \\
\hline Barthel & Pearson's correlation & $0.905^{* *}$ & $0.889^{* *}$ & $0.920^{* *}$ & $0.671^{* *}$ & $0.261^{*}$ \\
\hline
\end{tabular}

${ }^{* *}$ Correlation is significant at the 0.01 level (2-tailed). ${ }^{*}$ Correlation is significant at the 0.05 level (2-tailed).

TABLE 7: Responsiveness of A-ONE measured after 30 days of occupational therapy intervention.

\begin{tabular}{lccrr}
\hline & T0 Mean \pm SD & T1 Mean \pm SD & $Z$ & Sign. \\
\hline Dressing & $6.17 \pm 2.26$ & $12.53 \pm 4.30$ & $-5.093^{\mathrm{b}}$ & $-5.171^{\mathrm{b}}$ \\
Grooming and hygiene & $8 \pm 4.16$ & $13.44 \pm 3.56$ & $-4.943^{\mathrm{b}}$ & $<0.001$ \\
Transfers and mobility & $5.78 \pm 3.68$ & $11.53 \pm 4.54$ & $-4.422^{\mathrm{b}}$ & $<0.001$ \\
Feeding & $11.67 \pm 2.74$ & $13.22 \pm 1.97$ & $-3.216^{\mathrm{b}}$ & 0.001 \\
Communication & $7.11 \pm 1.19$ & $7.61 \pm 0.60$ & 0.001 \\
\hline
\end{tabular}

2.4. Responsiveness. To measure A-ONE responsiveness in a subpopulation of the sample, the Wilcoxon rank test $(p<0.05)$ was used in patients who performed an occupational therapy intervention. The range was calculated based on hospitalization timing during an intensive rehabilitation program, so responsiveness was evaluated at the discharge after 30 days from the first assessment.

\section{Results}

A total of 70 people having a diagnosis of neurological disorders were evaluated; the mean age is 74.66 (SD 7.88) years (range 60-89). The main characteristics of the sample are described in Table 1.

3.1. Reliability. The internal consistency of the A-ONE analyzed through Cronbach's alpha showed good values, ranging from 0.634 (in the domain of communication) to 0.930 (in the domain of transfers and mobility), while values for the total score were 0.959 . Table 2 summarizes data for internal consistency, while Table 3 reports item-total correlation.

All patients enrolled in the study were evaluated twice by the same rater one day after the first evaluation (intrarater reliability). As shown in Table 4, the ICC of all domains varied from 0.984 to 0.997 . Furthermore, interrater reliability showed values higher than 0.70 , which varied from 0.979 to 0.998, indicating a high agreement between the two evaluations. Results are summarized in Table 5.

3.2. Validity. The construct validity was evaluated using Pearson's correlation coefficient. Table 6 shows the results of the correlation between A-ONE and the Barthel index.

3.3. Responsiveness. Responsiveness was measured in 36 patients, compared to 70 of the population enrolled in the study. This is because only 36 patients received an occupational therapy intervention. Table 7 reports the main results. 


\section{Discussion}

The purpose of this study was to evaluate the psychometric properties of the A-ONE in an Italian population with CNS dysfunction. Aforementioned, the A-ONE is divided into two subscales: the Functional Independence scale and the Neurobehavioral Impairment scale [25]. The Neurobehavioral Impairment scale's original purpose was to determine the nature of problems that interfere with ADL task performance. The goal was to identify the type and severity of neurobehavioral impairment limiting the individual's independence in ADL tasks (e.g., motor apraxia, unilateral body neglect, and attention) and to gather the information that could be used to guide occupational therapy interventions [7]. Therefore, the present study reports only psychometric properties of the Functional Independence scale.

Cronbach's coefficient alpha of the Functional Independence subscale ranging from 0.634 to 0.930 was consistent with the original study ( $\alpha=0.75-0.79$ ). For reliability analysis, our result on interrater reliability reports very high values $(>0.95)$, in line with those reported by Arnadottir and colleagues (2008) (ICC $=0.98)$. However, to the best of our knowledge, no studies report values on intrarater reliability. Our study presents the first values of intrarater reliability and highlights the stability of the scale between raters.

Construct validity values reveal a good relationship with the Barthel index, except for the communication domain (0.261). The present result can be explained because the Barthel index does not measure communication at all.

Responsiveness was measured in a subsample population because the whole population has not received an occupational therapy intervention. Our results show that the AONE scale can register improvement after rehabilitation and can be used in current clinical practice.

Despite these encouraging results, the present study has some limitations. First of all, the lack of validation study in other countries does not compare some psychometric properties in different contexts. Second, the relatively small sample size does not allow to understand differences between different population. Further study should explore a bigger sample with different CNS diseases.

\section{Conclusion}

The present investigation reveals A-ONE as a valid and reliable tool when using with people with CNS dysfunction. Now, Italian occupational therapists can measure with more confidence activities of daily living and the performance of their clients.

\section{Data Availability}

The research data used to support the findings of this study are included within the article.

\section{Additional Points}

Implication for Rehabilitation. (i) The A-ONE assesses the independence in daily life activities and the impact of neuro- behavioral impairment on performance (no scale was developed to evaluate impairment impact on performance). (ii) It can be used for many neurological disorders in patients aged above 16. (iii) It is an occupation-based evaluation tool specific for occupational therapists. (iv) It helps in clinical reasoning, decision-making, and selection of intervention

\section{Ethical Approval}

All procedures followed the responsible committee's ethical standards on human experimentation (institutional and national) and with the Helsinki Declaration of 1975, as revised in 2008. We certify that all applicable institutional and governmental regulations concerning the ethical use of human volunteers were followed during this research.

\section{Consent}

Informed consent was obtained from all participants for being included in the study.

\section{Conflicts of Interest}

All authors declare no conflict of interest.

\section{Acknowledgments}

We acknowledge those who participated in the surveys; their collective expertise greatly informed the Italian version of the A-ONE.

\section{References}

[1] H. J. Kaminski, "The brain and behavior: assessing cortical dysfunction through activities of daily living (ADL)," Neurology, vol. 41, no. 3, p. 464, 1991.

[2] Ministero della Salute, La situazione sanitaria del paese. Malattie del Sistema Nervoso Centrale, 2018, http://www.rssp .salute.gov.it/rssp/paginaParagrafoRssp.jsp?sezione= situazione\&capitolo $=$ malattie\&id $=2655$.

[3] L. A. Legg, S. R. Lewis, O. J. Schofield-Robinson, A. Drummond, and P. Langhorne, "Occupational therapy for adults with problems in activities of daily living after stroke," Cochrane Database of Systematic Reviews, no. 7, article CD003585, 2017.

[4] M. Tofani, A. Ranieri, G. Fabbrini et al., "Efficacy of occupational therapy interventions on quality of life in patients with Parkinson's disease: a systematic review and meta-analysis," Movement Disorders Clinical Practice, vol. 7, no. 8, pp. 891$901,2020$.

[5] M. Tofani, E. Castelli, M. Sabbadini et al., "Examining reliability and validity of the Jebsen-Taylor hand function test among children with cerebral palsy," Perceptual and motor skills, vol. 127, no. 4, pp. 684-697, 2020.

[6] G. Árnadóttir, "Contributing to an integrated profession: a model-based examination of the A-ONE," Scandinavian Journal of Occupational Therapy, vol. 24, no. 2, pp. 98-108, 2016.

[7] G. Árnadóttir, A. G. Fisher, and B. Löfgren, "Dimensionality of nonmotor neurobehavioral impairments when observed in the natural contexts of ADL task performance," Neurorehabilitation and Neural Repair, vol. 23, no. 6, pp. 579-586, 2009. 
[8] G. Árnadóttir, B. Löfgren, and A. G. Fisher, "Neurobehavioral functions evaluated in naturalistic contexts: Rasch analysis of the A-ONE neurobehavioral impact scale," Scandinavian Journal of Occupational Therapy, vol. 19, no. 5, pp. 439-449, 2011.

[9] G. Árnadóttir, B. Löfgren, and A. G. Fisher, "Difference in impact of neurobehavioural dysfunction on activities of daily living performance between right and left hemispheric stroke," Journal of Rehabilitation Medicine, vol. 42, no. 10, pp. 903907, 2010.

[10] G. Árnadóttir and A. G. Fisher, "Rasch analysis of the ADL scale of the A-ONE," American Journal of Occupational Therapy, vol. 62, no. 1, pp. 51-60, 2008.

[11] Y. Higashi, S. Takabatake, A. Matsubara, K. Nishikawa, H. Shigeta, and G. Árnadóttir, "Reliability and validity of the Japanese version of the ADL-focused occupation-based neurobehavioural evaluation (A-ONE J): applying Rasch analysis methods," Hong Kong Journal of Occupational Therapy, vol. 32, no. 1, pp. 32-40, 2019.

[12] J. Kang, H.-Y. Park, J.-R. Kim, and J.-H. Park, "Validity and reliability of the Korean version of the activities of daily living (ADL)-focused occupation-based neurobehavioral evaluation (A-ONE)," American Journal of Occupational Therapy, vol. 73, 4, Supplement 1, 2019.

[13] G. Romagnoli, A. Leone, G. Romagnoli et al., "Occupational therapy's efficacy in children with Asperger's syndrome: a systematic review of randomized controlled trials," La Clinica Terapeutica, vol. 170, 2019.

[14] A. Berardi, E. Regoli, M. Tofani et al., "Tools to assess the quality of life in patients with Parkinson's disease: a systematic review," Expert Review of Pharmacoeconomics and Outcomes Research, vol. 21, no. 1, pp. 55-68, 2021.

[15] F. Panuccio, A. Berardi, M. A. Marquez et al., "Development of the Pregnancy and Motherhood Evaluation Questionnaire (PMEQ) for evaluating and measuring the impact of physical disability on pregnancy and the management of motherhood: a pilot study," Disability and Rehabilitation, pp. 1-7, 2020.

[16] M. Tofani, G. Galeoto, D. Cazzetta, A. Berardi, J. Sansoni, and D. Valente, "Validation of the pediatric evaluation of disability inventory in an Italian population with autism spectrum disorder: a cross-sectional study," La Clinica Terapeutica, vol. 170, 2019.

[17] M. Ioncoli, A. Berardi, M. Tofani et al., "Crosscultural Validation of the Community Integration Questionnaire-Revised in an Italian Population," Occupational Therapy International, vol. 2020, Article ID 8916541, 7 pages, 2020.

[18] A. Berardi, M. Saffioti, M. Tofani et al., "Internal consistency and validity of the Jebsen-Taylor hand function test in an Italian population with hemiparesis," NeuroRehabilitation, vol. 45, no. 3, pp. 331-339, 2019.

[19] M. Tofani, C. Candeloro, M. Sabbadini et al., "A study validating the Italian version of the level of sitting scale in children with cerebral palsy," Clinical Rehabilitation, vol. 33, no. 11, pp. 1810-1818, 2019.

[20] M. Tofani, M. Nobilia, G. Culicchia et al., “The Italian version of rheumatoid arthritis pain scale (IT-RAPS): psychometric properties on community and clinical samples," Reumatismo, vol. 71, no. 1, pp. 13-18, 2019.

[21] G. Galeoto, S. Turriziani, A. Berardi et al., "Levels of cognitive functioning assessment scale: Italian cross-cultural adaptation and validation," Annali di igiene : medicina preventiva e di comunità, vol. 32, 2020.
[22] G. Galeoto, M. C. Formica, N. B. Mercuri et al., "Evaluation of the psychometric properties of the Barthel index in an Italian ischemic stroke population in the acute phase: a crosssectional study," Functional Neurology, vol. 34, 2019.

[23] F. Panuccio, G. Galeoto, M. A. Marquez et al., "Internal consistency and validity of the Italian version of the Jebsen- Taylor hand function test (JTHFT-IT) in people with tetraplegia," Spinal Cord, vol. 59, no. 3, pp. 266-273, 2021.

[24] F. Miniera, A. Berardi, F. Panuccio, D. Valente, M. Tofani, and G. Galeoto, "Measuring environmental barriers: validation and cultural adaptation of the Italian version of the Craig Hospital Inventory of Environmental Factors (CHIEF) scale," Occupational Therapy In Health Care, vol. 34, no. 4, pp. 373-385, 2020.

[25] S. Gardarsdóttir and S. Kaplan, "Validity of the Arnadottir OT-ADL neurobehavioral evaluation (A-ONE): performance in activities of daily living and neurobehavioral impairments of persons with left and right hemisphere damage," American Journal of Occupational Therapy, vol. 56, no. 5, pp. 499-508, 2002.

[26] G. Galeoto, R. De Santis, A. Marcolini, A. Cinelli, and R. Cecchi, "The informed consent in occupational therapy: proposal of forms," Giornale Italiano di Medicina del Lavoro ed Ergonomia, vol. 38, no. 2, pp. 107-115, 2016.

[27] J. E. Lexell and D. Y. Downham, "How to assess the reliability of measurements in rehabilitation," American Journal of Physical Medicine and Rehabilitation, vol. 84, no. 9, pp. 719-723, 2005.

[28] P. E. Shrout and J. L. Fleiss, "Intraclass correlations: uses in assessing rater reliability," Psychological Bulletin, vol. 86, no. 2, pp. $420-428,1979$.

[29] B. Ratner, "The correlation coefficient: its values range between $+1 /-1$, or do they?" Journal of Targeting, Measurement and Analysis for Marketing, vol. 17, no. 2, pp. 139-142, 2009. 